\title{
Operative Treatment of an Atypical Segmental Bipolar Fracture of the Clavicle
}

\author{
Nikolaos Varelas, ${ }^{1}$ Pieter Joosse, ${ }^{2}$ and Philippe Zermatten ${ }^{1, *}$ \\ ${ }^{1}$ Department of Surgery, Division of Orthopaedic Surgery and Traumatology, Centre Hospitalier du Centre du Valais, Sion, Switzerland \\ ${ }^{2}$ Department of Surgery, Medisch Centrum Alkmaar, Alkmaar, The Netherlands \\ ${ }^{*}$ Corresponding author: Philippe Zermatten, Department of Surgery, Division of Orthopaedic Surgery and Traumatology, Centre Hospitalier du Centre du Valais, Sion, Switzerland. \\ Tel:+41-276038885, Fax:+41-276034438, E-mail: philippe.zermatten@hopitalvs.ch
}

Received 2015 May 12; Accepted 2015 June 6.

\begin{abstract}
Introduction: Clavicle fractures are very common, accounting for approximately $4 \%$ of all adult fractures. Segmental bipolar fractures involving the lateral and the medial ends of the clavicle are extremely rare, with only isolated cases reported in the literature. The injury mechanism is often unclear and the management of these fractures remains controversial.

Case presentation: Here is to report a case of a segmental bipolar fracture of the clavicle with a lateral fracture and a displaced medial fracture without dislocation of the sternoclavicular joint following a low energy fall to the outstretched hand, and discuss its management. Conclusions: Stability of the clavicle is crucial for shoulder function and care should be taken not to miss or underestimate segmental bipolar fractures even with a low energy mechanism. Authors believe that operative treatment should be taken into consideration for displaced fractures.
\end{abstract}

Keywords: Clavicle, Bone Fracture, Bipolar, Care Management

\section{Introduction}

Clavicle fractures are very common, accounting for approximately $4 \%$ of all adult fractures and $44 \%$ of which occur in the shoulder girdle (1). Nevertheless, medial fractures are rare accounting for $2 \%-3 \%$ of all clavicle fractures (2). Segmental bipolar fractures involving the lateral and the medial ends of the clavicle are even rarer, with only isolated cases reported in the literature. The injury mechanism is often unclear and the management of these fractures remains controversial (3). Bipolar clavicle fractures usually involve the midshaft and the lateral end of the bone and it is thought that they occur more often as a result of high energy trauma with concomitant multiple injuries (4).

Here is to report a case of a segmental bipolar fracture of the clavicle with a minimally displaced lateral fracture and a displaced medial fracture without dislocation of the sternoclavicular joint following a low energy fall to the outstretched hand, and discuss its management.

\section{Case Presentation}

A 68-year-old female, right hand dominant, slipped on ice and fell on her left outstretched hand. There were no open wound, no neurovascular deficit and no other significant injuries. The skin was not at risk. Standard $\mathrm{x}$-rays of the shoulder girdle showed a minimally dis- placed lateral fracture and a second displaced medial fracture of the left clavicle. A conservative treatment was proposed with regard to the patient's age and her low functional demand. A week later the assessment was completed by a computed tomography (CT) scan which underlined a displaced medial fracture with shortening of the clavicle bone (Figure 1). This statement drove us to propose a final fixation of the clavicle by means of two locking plates. The hardware used consisted of two 3.5/2.7 locking compression (LC) anatomical plates with a lateral extension (DePuy Synthes®, United States). A left sided plate was used for the lateral fracture and placed cranially while a right sided plate was used for the medial fracture and placed anteriorly. The patient was operated in beach chair position under general anesthesia. Antibiotic prophylaxis was given at the induction. A longitudinal anterior incision was used. The reduction of the medial side of the intermediate segment of the clavicle was particularly difficult due to the small medial fragment still attached to the sternoclavicular joint, and the rupture of the costoclavicular ligament and the lever arm produced by the coracoclavicular ligaments still attached to the lateral side of the intermediate fragment. Fixation of the lateral fracture facilitated the reduction and fixation of the medial fracture. Three $2.7 \mathrm{~mm}$ locking screws were placed in the medial frag-

Copyright (c) 2015, Kashan University of Medical Sciences. This is an open-access article distributed under the terms of the Creative Commons Attribution-NonCommercial 4.0 International License (http://creativecommons.org/licenses/by-nc/4.0/) which permits copy and redistribute the material just in noncommercial usages, provided the original work is properly cited. 
Varelas $N$ et al.

ment and stabilized the sternoclavicular joint by means of a transosseous non-resorbable suture of \#2 FiberWire (Arthrex®, United States) running through two holes of the extension of the right sided plate placed anteriorly and through two tunnels of $2 \mathrm{~mm}$ of diameter drilled in the manubrium. Early passive and active mobilization of the left shoulder was begun from the second postoperative day. A sling was used for six weeks as antalgic support and the abduction of the left arm was limited to $90^{\circ}$ during this period because of the poor quality of the clavicle bone and the relative stability of the fixation of the medial fracture. After six weeks the patient was practically pain free and presented a limitation of the range of shoulder motion. After three months the patient was able to completely move her left shoulder. After six months bony consolidation of the clavicle was achieved (Figure 2). After the last control (at $12^{\text {th }}$ months) the Disabilities of the Arm, Shoulder and hand (DASH) score was 5.0 and there was no significant hardware irritation.

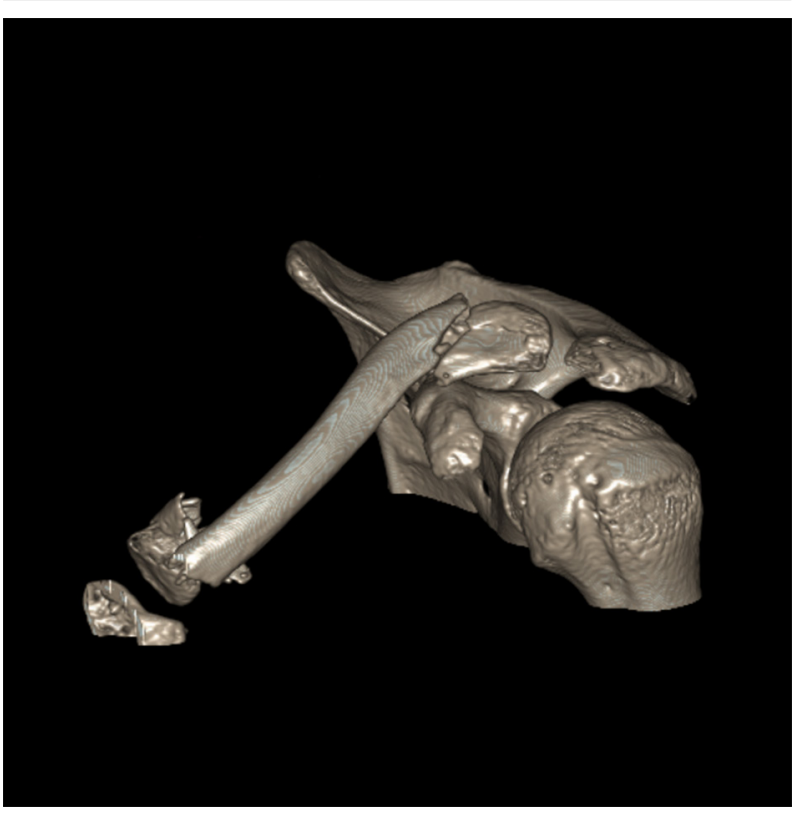

Figure 1. Computed Tomography Three-Dimensional Reconstruction of the Left Shoulder Girdle Showing Displaced Medial Fracture and Oblique Lateral Fracture With Shortening of the Clavicle Bone

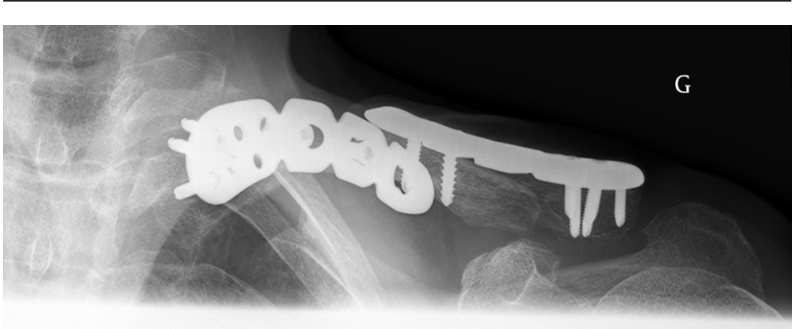

Figure 2. X-Ray at Sixth Month; Axial View of the Left Clavicle Showing Signs of Consolidation

\section{Discussion}

From the first time a case of bipolar clavicular lesion was described in 1831 by Porral (5) until today there is neither consensus nor universally accepted guidelines concerning the management of segmental bipolar fractures of the clavicle, mainly due to the limited number of cases reported in the literature.

First of all, it should be highlighted that medial fractures of the clavicle should be investigated by a CT-scan because they are frequently misdiagnosed or underestimated without considering the high risk of concomitant lesions like rib fractures, sternoclavicular dislocations and pneumothorax. A CT-scan is also very useful in the postoperative follow-up because of the superposition of the thorax to the proximal clavicle.

The mechanism of these double segmental fractures reported by most authors is either a high energy trauma or two separate successive injuries. In the current study, the patient described a low energy fall on the outstretched hand and had no other concomitant injuries. A plausible explanation is provided by Stanley et al. (6) who suggest that, after the first contact of the outstretched hand on the ground, the fall continues because of the patient's body weight and falling velocity sustaining a secondary direct blow to the shoulder.

To manage such fractures, it is clear that non displaced fractures could and should be treated non operatively (3, 7). Even highly displaced bipolar fractures of the clavicle are treated conservatively with excellent results (8); the high risk of nonunion with one of the two fractures uniting and the other one should not be considered. This is documented for other long bones (9) and small series or case reports suggest that it may be also the case for the clavicle (10). In addition to the risk of nonunion, the authors feel that neutralization of the lever motion by fixing both sides of a segmental bipolar fracture of the clavicle provides stability and limits the need for more rigid fixations especially at the sternoclavicular joint. The choice of technique and implants is challenging for medial fractures (4). Different techniques are described such as K-wires and tension bands $(11,12)$, lag screws, locking plates $(13,14)$ or hook plates $(15)$. Authors' choice was angular stable implants by means of two LC-plates. Evidence in the literature suggests that LC-plates of the clavicle present less deflection at failure and less plate looseness (16). In the current case the small medial fragment could lead some surgeons to fix the sternoclavicular joint by means of a hook plate or a temporary sternoclavicular fixation. Such a techniques are described and performed with success $(10,15)$, but a second operation is necessary for partial or complete removal of the hardware. Authors decided to stabilize the sternoclavicular joint with a transosseous nonresorbable suture attached onto the plate using two tunnels of $2 \mathrm{~mm}$ of diameter drilled in the manubrium.

Stability of the clavicle is crucial for shoulder function 
and care should be taken not to miss or underestimate segmental bipolar fractures even with a low energy mechanism. Authors believe that operative treatment should be taken into consideration for displaced fractures. In the current case, fixation with two locking plates at both ends of the clavicle led to fracture healing with a good functional outcome.

Considering the limited number of segmental bipolar fractures of the clavicle that a surgeon should treat during his/her career and the paucity of cases described in the literature, authors believe that sharing information and therapeutic options is useful and could contribute to work out a consensus in the management of these unusual lesions.

\section{Footnote}

Authors' Contribution:Preparing the manuscript: Nikolaos Varelas; editing the manuscript: Pieter Joosse and Philippe Zermatten.

\section{References}

1. Nordqvist A, Petersson C. The incidence of fractures of the clavicle. Clin Orthop Relat Res. 1994;(300):127-32. [PubMed: 8131324]

2. Postacchini F, Gumina S, De Santis P, Albo F. Epidemiology of clavicle fractures. J Shoulder Elbow Surg. 2002;11(5):452-6. [PubMed: 12378163]

3. Khan LA, Bradnock TJ, Scott C, Robinson CM. Fractures of the clavicle. J Bone Joint Surg Am. 2009;91(2):447-60. doi: 10.2106/ JBJS.H.00034. [PubMed: 19181992]

4. Throckmorton T, Kuhn JE. Fractures of the medial end of the clavicle. J Shoulder Elbow Surg. 2007;16(1):49-54. doi: 10.1016/j. jse.2006.05.010. [PubMed:17169583]

5. Porral MA. Observation d'une double luxation de la clavicule droite. J Univ Hebd Med Chir Prat. 1831;2:78-82.
6. Stanley D, Trowbridge EA, Norris SH. The mechanism of clavicular fracture. A clinical and biomechanical analysis. J Bone Joint Surg Br. 1988;70(3):461-4. [PubMed: 3372571]

7. Sethi K, Newman SD, Bhattacharya R. An unusual case of bipolar segmental clavicle fracture. Orthop Rev (Pavia). 2012;4(3):e26. doi: 10.4081/or.2012.e26. [PubMed: 23066494]

8. Gouse M, Jacob KM, Poonnoose PM. Traumatic floating clavicle: a case report and literature review. Case Rep Orthop. 2013;2013:386089. doi: 10.1155/2013/386089. [PubMed: 24381774]

9. Keating JF, Kuo RS, Court-Brown CM. Bifocal fractures of the tibia and fibula. Incidence, classification and treatment. J Bone Joint Surg Br.1994;76(3):395-400. [PubMed: 8175840]

10. Skedros JG, Knight AN, Mears CS, Langston TD. Temporary sternoclavicular plating for an unusual double clavicle fracture (medial nonunion, lateral acute) complicated by an intraoperative pneumothorax. Case Rep Orthop. 2014;2014:206125. doi: 10.1155/2014/206125. [PubMed:25258689]

11. Scapinelli R. Bipolar dislocation of the clavicle: 3D CT imaging and delayed surgical correction of a case. Arch Orthop Trauma Surg. 2004;124(6):421-4. doi: 10.1007/s00402-004-0669-2. [PubMed:15103475]

12. Falcone MO, Guinand R, Bachour F, Haidar N, Fontaine C, Chantelot C. [Bifocal fracture of sternal end of clavicle-pseudodislocation of sternoclavicular joint. Report of a case]. Chir Main. 2007;26(1):50-4. doi: 10.1016/j.main.2007.01.002. [PubMed: 17418772]

13. Heywood R, Clasper J. An unusual case of segmental clavicle fracture. J R Army Med Corps. 2005;151(2):93-4. [PubMed: 16097113]

14. Daolagupu AK, Gogoi PJ, Mudiganty S. A rare case of segmental clavicle fracture in an adolescent. Case Rep Orthop. 2013;2013:248159. doi: 10.1155/2013/248159. [PubMed: 23476850]

15. Gille J, Schulz A, Wallstabe S, Unger A, Voigt C, Faschingbauer M. Hook plate for medial clavicle fracture. Indian J Orthop. 2010;44(2):221-3. doi: 10.4103/0019-5413.61768. [PubMed: 20419013]

16. Will R, Englund R, Lubahn J, Cooney TE. Locking plates have increased torsional stiffness compared to standard plates in a segmental defect model of clavicle fracture. Arch Orthop Trauma Surg. 2011;131(6):841-7. doi: 10.1007/s0 0402-010-1240-y. [PubMed: 21188395] 